\title{
The Dove Club: Challenging Perceptions of Body Weight in Elementary School
}

\author{
KELSEY IOANNONI, York University
}

\begin{abstract}
This paper examines the creation of the Dove Club, an initiative at a Peel District Elementary School, by asking how the creation of the Dove Club is situated in a broader discussion of healthism and the increase in popular concern surrounding the alleged obesity epidemic. Reviewing the literature on the "obesity epidemic," fat studies, and education, I highlight the impact of the "obesity epidemic" discourse on schools. In this paper, I analyze the mission statement of the Dove Club, and personal correspondence with a founding teacher. Using a social constructionist lens, I argue that the Dove Club reconstructs claims of health and healthy living by positioning teachers as key role models for young female students. Additionally, the Dove Club focuses on aspects of health, such as positive self-esteem, role modeling, and healthy living that are not intrinsically linked to weight. I interpret these actions as successful contributions to health by employing a Health At Every Size lens.
\end{abstract}

Key words: Health, Schools, Healthy Living, “Obesity Epidemic”, Health At Every Size, Fat Studies 


\section{Introduction}

In September 2013, a school in the Peel District of Ontario launched an inaugural initiative influenced by Dove's Real Women campaign called the Dove Club. This club aims to empower young girls, promote healthy living and foster positive self-esteem. Several teachers initiated the program in hopes of having a positive influence on their students, and the Club has been chronicled by news organizations such as CTV News. This extracurricular club meets after school and includes young girls from grades 5 or 6, generally between 10-12 years old, who were selected by their teachers as students who could potentially benefit from confidence building activities. While this club was inspired by the Dove's Real Women campaign, the Dove Club is not actually affiliated with the corporation. Instead, teachers designed a program that would target young girls, their conceptualizations of health, healthy living, and self-esteem.

In exploring this research question, I provide a brief introduction to the "obesity epidemic" and its influence on schools. I then conduct a qualitative content analysis analyzing the statement of the Dove Club online, supplemented by a discussion of personal communication I have had with one of the founding teachers. I conclude this paper with discussion of my findings and implications for future research.

Fat studies has emerged as a radical, interdisciplinary field that targets the root of weightrelated belief systems (Wann, 2009). This field requires challenges the power-ridden and prejudicial assumptions of weight-based beliefs (Wann, 2009). The focus on the body by early feminists centered primarily on eating disorders and self-consciousness; however, fat studies emerged in response to the increase of concern around, and the social construction of, obesity (Gard \& Wright, 2005). 
The "obesity epidemic" contributes to the marginalization and mistreatment of those considered obese through the diagnosis of "obesity" as a disease. The diagnosis of a condition as a disease is central in the way in which medicine demonstrates social control (Jutel, 2009). As Jutel (2009) notes, "giving the name is often the starting point for social labellers ...[and] diagnosis formalizes conditions that either individual or society identifies as problematic", (p. 61). Such diagnosis compels people to follow normative obligations to treat their disease. Jutel (2009) argues that, since the end of the twentieth century, being overweight has come to bear disease status. This occurred in response to the medical community facilitating claims regarding weight and health.

Fat studies scholars challenge the way in which scientific "truths" about obesity have been reconceptualized to influence the way in which people understand their bodies and their health. Of particular importance to this paper is the way in which these scientific "truths" have come to influence the way health is promoted in curricula for students and the consequences of a health management model on the way young students understand their bodies and health. Health professionals, according to Beausoleil (2009), have conflated a healthy lifestyle with thinness, and an unhealthy lifestyle with obesity, which has become instrumental in fostering disordered eating.

Childhood obesity is viewed with particular concern, as it is argued that there is a clear relationship between health, weight, and economic impact on the nation (Wright, 2009). Children are constructed as an 'at risk' population in need of intervention, which comes in the form of normalizing discourses on food type and intake and body shape, as well as constructions of normalized health and obesity as problematic (Harwood, 2009). 
In Canada, issues of health and wellness are addressed through campaigns that focus on 'healthy eating' and 'active living', which are primarily individual lifestyle choices (Beausoleil, 2009). Beausoleil (2009) posits that young people in Canada conflate health, fitness, and beauty and often times draw on thinness, being 'in shape', and not being fat as representations of health (Beausoleil, 2009; Rail, 2009). Beausoleil (2009) argues that dominant sexist and ableist social relations, as well as dominant discourses of beauty more broadly shape this perception.

The impacts of health discourses on education are vast. Curricula and pedagogies are being reshaped in Western schools in order to address initiatives and policies that aim to tackle the alleged childhood obesity epidemic (Rich \& Evans, 2009). Rich and Evans (2009) note that the representation of obesity as an epidemic has greatly influenced the social and material environments of schools by presenting students as 'at risk' for obesity and therefore subject to 'health interventions'. Health and physical education curricula are being called on to respond to the rising epidemic, demonstrated through the proliferation of teaching strategies and programs that aim to influence individual bodily practices in efforts to prevent obesity (Leahy, 2009). Harwood (2009) argues that "at a micro level, teachers and others can direct and discipline individuals regarding true discourses, acting as pedagogues in an individualizing and disciplinary process" (p. 24). Health and physical education curricula are then positioned to best address the supposed risk faced by students by providing them with knowledge and skills to reduce such risk (Leahy, 2009).

McVey, Gusella, Tweed, and Ferrari (2009) highlight that body image and weight loss are major concerns in many schools. Health curriculum often includes the promotion of 'ideal' weights for children, and these ideals can have negative consequences on students' understandings of their bodies. For example, the promotion of 'ideal' weight can increase the 
anxiety students have over their weight while disregarding socio-cultural or economic reasons for somatic diversity. As such, McVey and colleagues (2009) note that the use of weight based standards and testing in classrooms may lead to students engaging in unhealthy eating and dieting behaviours in order to achieve certain weight goals promoted in the curriculum.

Efforts taken to combat childhood obesity have been executed through curricula focusing on healthy eating and healthy weight. These curricula, according to Pinhas, McVey, Walker, Norris, Katzman, and Collier (2013), recommend that students decrease their caloric and fat intake while increasing their physical activity and promoting calorie burning as measures to achieve a supposed healthy weight. This prescriptive curricula, says Pinhas et al (2009), can backfire when educators give the task of regulating and monitoring children's health practices without being educated on or sensitized to the vulnerability of children in internalizing these messages.

As the impact of a health curriculum is immense, negatively or positively (McVey et al., 2009), teachers then are best positioned and have the responsibility to ensure balance among the messages their students are receiving about healthy eating and active living (Harwood, 2009; Leahy, 2009; McVey et al., 2009; Rich \& Evans, 2009). Teachers are crucial, because they act as both educators and role models for their students (McVey et al., 2009). If teachers are empowered to foster a healthy school climate and have access to resources to do so, McVey and colleagues (2009) argue that they can foster a healthy school climate and promote wellness among students without instilling anxiety about weight.

\section{Conceptual Framework}

This paper is situated in the discourses of fat studies, discussions of healthism, and Health At Every Size (HAES). The discourse of healthism suggests that health centres on the size and 
shape of bodies, and that an appropriate body size can be easily achieved through hard work and discipline (Crawford, in Lee \& MacDonald, 2010). In the discourse of healthism, it is individual responsibility that governs healthy living and healthy choices, positioning those who fail to conform to the thin ideal as lazy or failures (Rich and Evans, in Lee \& MacDonald, 2010).

The HAES perspective differs from conventional constructions of health, and focuses on healthy day-to-day practices and positive self-acceptance (Burgard, 2009). Shifting the discourse of health as intrinsically related to weight to a discourse of health as related to a set of practices is important to fat studies scholars. The language of the "obesity epidemic" and the use of BMI as a measure of health are problematic (see Flegal et al., 2005; Flegal et al., 2013), and many scholars argue for a shift to a health at every size (HAES) perspective.

As Bacon, Stern, Loan, and Keim (2005) highlight, dieting has become a part of our cultural identity. As the research on the supposed success of dieting as a way to improve health becomes more heavily criticized, a paradigm shift away from dieting is necessary in order to focus on healthy behaviours rather than weight loss (Bacon et al., 2005). Alternatively, Bacon and colleagues (Bacon et al., 2005; Bacon \& Aphramor, 2011; Burgard, 2009) call for a model of health that focuses on teaching intuitive eating and reliance on body cues, and they promote a health at every size model that does not conflate weight and health. Bacon and colleagues (2005) found that participants engaging in the HAES paradigm sustained the implemented restraint patterns at subsequent follow ups, as well as maintaining many improvements to their metabolic functioning and energy expenditure over participants engaged in traditional dieting, Whereas the weight loss group in Bacon et al.'s 2005 study did not show significant results, the HAES group maintained their weight while improving their health risk indicators after a two-year follow up. 
As weight-focused paradigms of health are ineffective in turning citizens into thinner or healthier people, a HAES paradigm shift would be significantly more beneficial (Bacon et al., 2005; Bacon \& Aphramor, 2011; Burgard, 2009). Consequently, a weight-based focus on health produces a preoccupation with weight loss that detracts from goals associated with overall good mental and physical health. In order to support healthy behaviour and recognize that health and weight are not mutually exclusive, HAES shifts rom a failing perspective of health management to health promotion (Bacon \& Aphramor, 2011).

\section{Methodology}

In addition to reviewing existing scholarship on fat studies and the "obesity epidemic," I analyzed the mission statement of the Dove Club from the school district's website (see Appendix A for full statement) in order to address how the creation of the Dove Club is situated in a broader discussion of healthism and the "obesity epidemic." As well, I reviewed the personal correspondence I had engaged in with one of the organizing teachers of the Dove Club. With her permission $^{1}$, I additionally analyzed the email correspondence, and I asked her questions about the delivery of content, the curricula in which the program runs, the frequency of the program, and age demographics of students in the club in an effort to contextualize the information provided in the club's mission statement.

In analyzing this data, I use qualitative content analysis, which can be defined as "a research method for the subjective interpretation of the content of text data through the systemic classification process of coding and identifying themes or patterns" (Hsieh \& Shannon, 2005, p 1278). Similarly, Patton (2002) describes qualitative content analysis as "qualitative data

\footnotetext{
${ }^{1}$ In consultation with the Office of Research Ethics at York University, it was determined that ethics approval would not be required for reviewing this communication, as the organizer provided me with informational data about the program itself.
} 
reduction and sense-making effort ... [that] attempts to identify core consistencies and meanings" ( $\mathrm{p} 453)$. Conducting a qualitative content analysis allows for the uncovering of social reality in both a subjective and scientific fashion (Zhang \& Wildemuth, 2009) by examining the way in which the creation of the Dove Club is situated in the context of healthism and the obesity epidemic.

\section{Results and Analysis}

In analyzing the mission statement of the Dove Club, available on the school district's website, as well as the personal email correspondence between myself and a key teacher at this elementary school, I have identified two key themes in situating the creation of the Dove Club in the broader context of the obesity epidemic.

\section{Theme 1: Reconstructing Claims and Claims Makers}

The first key theme present in both the Club's document and my correspondence with a teacher at the school was the reconstruction of claims and claims-makers. As highlighted in literature review (Beausoleil, 2009; Jutel, 2009), the medical community and the media both hold significant weight in constructing the connection between health, weight, and beauty. This reconstruction of claims is evidenced through the mission statement that appears online, for example "the idea started with a simple question: 'How do we instill positive self image in young girls when they are constantly exposed to a world filled with unrealistic and mixed media messages?"” (Dove Club Statement, 2014).

The teachers at this school aim to challenge this construction with competing claims of health by focusing on mental well-being, positive role modeling, relationship building, and leadership. In my personal correspondence with the teacher, she indicated that the teachers 
"looked at the needs of the girls, the messages that were less than favourable in the media that [they] wanted to raise their awareness around" (Personal Correspondence, October 2014).

What is key, though, in this reconstruction is that the teachers place themselves as role models, which positions them with authority outside of the student-teacher relationship. As noted earlier, Harwood (2009) states that "at a micro level, teachers and others can direct and discipline individuals regarding true discourses, acting as pedagogues in an individiualising and disciplinary process" (p.24).

In this case, the teachers are trying to reconstruct more holistic and positive understandings of health. They view themselves as positive role models for the young girls in this club, positioning themselves as alternative claims-makers in contrast to the dominant claimsmakers, for example, the media. This is evident in my personal communication with one of the founding teachers of the Dove Club, where she indicated that "[the students] needed a group of positive female role models who could help them see their own personal beauty, their potential and all of the things that make them, as individuals, amazing" (Teacher, October 2014).

\section{Theme 2: Reconstruction of Solutions}

A second key theme was the reconstruction of solutions. Key in social construction and the increased popular concern over an "obesity crisis" is what can be done to solve a situation. In discussing the "obesity epidemic", it is often extreme dieting and exercise that is prescribed in order to fix the alleged disease. As Harwood (2009) suggests, the medicalization of obesity leads to an individualized and normalized sense of treatment, which Rail (2009) suggests would create disordered eating and physical habits in otherwise thin children.

The Dove Club takes a holistic approach at health by not equating health with weight, which pushes for a reconstruction of the understanding that students have about health. As Rail 
indicates in her research on students in Newfoundland and Labrador, students understand health, weight, and beauty as conflated. The Dove Club challenges this, as evident in their mandate, which indicates that in empowering young girls, they focus on four pillars: health and mental well-being, positive role-modelling, relationship building, and leadership beyond the classroom. Specifically, according to their mission statement, health and mental well-being focuses on "providing young girls with hands on learning experiences that promote and teach them how to lead healthy life styles at an early age" (Dove Club Statement, 2014.). This suggests the teaching of healthy lifestyles, which is significantly more holistic than the teaching of supposed healthy dieting. For example, one of the founding teachers indicated to me that "throughout the 10 weeks we were together, we worked with the girls to prepare healthy meals ... we also ran once each week with them, and did one other kind of exercise during each week."

Extrapolating from focusing on healthy eating and daily practices, the Dove Club extends its understanding of health to cover issues of healthy relationship building, positive self-image, and mental health. Further correspondence with the teacher involved in planning this club (December, 2014) indicated that they covered a wide range of topics that included creating safe spaces, building positive relationships, maintaining healthy bodies, increasing cultural acceptance and social media awareness, inculcating self awareness, and encouraging women in leadership roles.

\section{Discussion}

The "obesity epidemic" is one of the most powerful discourses that influences the way in which health and bodies are conceptualized (Wright, 2009). Wright (2009) argues that the alleged truths about the "obesity epidemic" have been reconceputalized by government policy, health promotion initiatives, online resources, and in-school practices, all of which influence 
how young people come to understand themselves. Children and young people come to know themselves in ways that have been constructed by claims makers. Wright conceptualizes this construction of knowledge as a range of biopedagogies, which reflects the "normalizing and regulating practices in schools [that are] disseminated more widely through the web and other forms of media, which have been generated by escalating concerns over claims of global 'obesity epidemic"” (Wright, 2009, p. 1). People, and in this instance young students, are then placed under constant monitoring and self-surveillance. The way in which obesity has been medicalized and constructed as a disease has influenced the monitoring of those who could be seen as "at risk" or requiring treatment for such disease.

The Dove Club steps in here as a form of intervention against the way in which health is conceptualized and the conflation of health with thinness. Instead of focusing on weight loss and caloric restriction, the Dove Club instead strives for modeling healthy living around positive selfesteem, healthy practices, and good role-modeling, in anticipation that these traits will permeate other areas of these young girls lives.

While teachers serve as role models for their students, their impact is not always positive. As McVey and colleagues (2009) point out, teachers carry with them their biases, and these biases can be reflected in how the curricula is taught. In testing out different forms of body positive, health promotion style curricula with educators, McVey et al., (2009) found that educating teachers in more health positive approaches, similar to HAES, makes teachers more conscious of the health material they are teaching. If this is true, then a change to the health curriculum to focus on a HAES, or similar, approach is necessary to transform the way students feel about their relationships with food, health, and healthy living. As teachers are the gatekeepers to students' learning about health (Harwood, 2009; Leahy, 2009; McVey et al., 
2009; Pinhas et al., 2013; Rich \& Evans, 2009), it is then their responsibility to ensure that their students are learning about health in a safe way: from a health promotion perspective that focuses on modeling healthy living as a lifestyle, and not a weight-based understanding of health.

HAES is being widely adopted by organizations focused on eating disorders to those focused on the advancement of size diversity (Bacon \& Aphramor, 2011). A series of clinical studies, such as the aforementioned Bacon et al., (2005), that compare HAES with other forms of obesity treatment found that HAES has relative health improvements across physiological, psychological, and health measures (Bacon \& Aphramor, 2011). As children learn about their health through biopedagogies, a shift in understandings of health in school are crucial. As a HAES model is shown through research (Bacon et al., 2005; Bacon \& Aphramor, 2011) to have significant long term effects on healthy living practices, the implementation of HAES material into school curricula would help shift understandings of health from health management to health promotion.

The Dove Club makes significant progress in breaking down weight-based understandings of health, and teaching students how to live positive, healthy lives. One critique that emerges, however, is that they appear to re-strengthen the bonds that connect health and self-esteem or self-worth, which cannot be understood as mutually exclusive. For example, "These experiences [at the Dove Club] are what every girl needs to develop a positive image and lead a healthy and happy life" (Dove Club Statement, 2014). Furthermore their indicated mission is "to empower young girls by providing the necessary tools to promote positive selfimage and healthy living" (Dove Club Statement, 2014). The connection between healthy living and self-esteem problematically links health with self-esteem. In moving forward, the Club, as 
well as other school curricula that deal with health and healthy living, should work to prevent the conflation of health with self-esteem.

A final critique I offer addresses the nature of the name of this afterschool program, and not of the content. As the teacher indicated to me, she and her colleagues were inspired by Dove's Real Women campaign, a campaign that promotes body diversity and positive selfesteem among women. While the Dove Club is not actually affiliated with Dove, the message Dove as a company sends has come under fire recently as being contradictory. Unilever, a parent company that also owns Axe Body Spray, owns Dove. For example, as US News points out (Kurtziben, 2013), an internal contradiction exists between the branding of the real women messaging of Dove, and the arguably sexist, objectification of women messaging behind Axe's campaigns. While this appears to have little impact on the actual Dove Club itself, it is interesting to note the tension that exists underscoring the Dove Real Women campaign.

\section{Conclusion}

When I asked the founding teacher to comment on the success of the Dove Club, she said teachers commented quite often on the differences they saw in the girls in class (speaking up more, participation increasing) and we even had some students get on stage during a French play to volunteer - something we wouldn't have seen form them before ... We felt that [the] Dove [Club] and the confidence building we did with them was a contributing factor in them doing this (Personal correspondence, December 2014).

In seeing such success, the school has chosen to run the Dove Club again this year with a new batch of grade 5-6 girls in the hope of achieving similar results.

In my analysis of this club and situation its creation in the broader context of the obesity epidemic and the Health at Every Size framework, I see the Dove Club as having made great 
strides at deconstructing weight and health. This club provides a more holistic view of health in terms of focusing on healthy practices and lifestyles as opposed to weight based understandings of health, although there is a significant tension between the understandings of health and positive self-image.

In moving forward with examining the effects of such a club on contributing to healthy lifestyles of young female students, it would be useful to speak with the students actually involved with the Dove Club to understand their perspective and attitude shifts. This research could be undertaken through individual interviews with students to understand their lived experiences.

The data for this paper came from the mission statement of the Dove Club, accessible on the district website, and from personal communications with a teacher involved in the creation of the Club. Both sets of data are limited in that they reflect only the positive nature of the Club. In efforts to get a more nuanced understanding of this Club, future research could involve an ethnographic study where the researcher actually attends the weekly meetings.

Finally, more research is needed on strategies and pedagogies of teaching health to students from a Health at Every Size perspective. This could be conducted through in-depth interviews with health and physical education teachers to understand their teaching strategies, coupled with a thorough examination of the health and physical education curriculum documents. 


\section{References}

Bacon, L., \& Aphramor, L. (2011). Weight science: Evaluating the evidence for a paradigm shift. Nutrition Journal, 10(9), 1-13.

Bacon, L., Stern, J., Van Loan, M., \& Keim, N. (2005). Size acceptance and intuitive eating improve health for obese, female chronic dieters. Journal of the American Dietetic Association, 105(6), 929-936.

Beausoleil, N. (2009). An impossible task?: Preventing disordered eating in the context of the current obesity panic. In J. Wright \& V. Harwood (Eds). Biopolitics and the 'Obesity Epidemic’: Governing Bodies. New York: Routledge.

Burgard, D., Dykewomon, E., Rothblum, E., \& Thomas, P. (2009). Are we ready to throw our weight around? Fat studies and political activism. In E. Rothblum \& S. Solovay (Eds.). The Fat Studies Reader. New York: New York University Press.

Campos, P. (2004). The obesity myth: Why America's obsession with weight is hazardous to your health. New York, NY: Gotham Books.

Dove Club Statement (2014). Retrieved from http://www.peelschools.org/Documents/Dove\%20Club\%20Peel\%20Statement.pdf

Flegal, K., Graubard, B., Williamson, D., \& Gail, M. (2005). Excess death associated with underweight overweight and obesity. Journal of American Medical Association, 293(15), 1861-1867.

Flegal, K., Kit, B., Orpana, H., \& Graubard, B. (2013). Association of all-cause mortality with overweight and obesity using standard body mass index categories. Journal of American Medical Association, 309(1), 71-82.

Gard, M. \& Wright, J. (2005). The Obesity Epidemic: Science, Morality, and Ideology. New 
York, NY: Taylor \& Francis Inc.

Harwood, V. (2009). Theorizing biopedagogies. In J. Wright \& V. Harwood (Eds). Biopolitics and the 'Obesity Epidemic': Governing Bodies. New York: Routledge.

Jutel, A. (2009). Doctor's orders: Diagnosis, medical authority and the exploitation of the fat body. In J. Wright \& V. Harwood (Eds). Biopolitics and the 'Obesity Epidemic': Governing Bodies. New York: Routledge.

Kurtziben, D. (2013, April 18). Do Dove and Axe sell the same message? US News. Retrieved from http://www.usnews.com/news/articles/2013/04/18/unilever-faces-criticism-for-realbeauty-ad-campaign

Leahy, D. (2009). Disgusting pedagogies. In J. Wright \& V. Harwood (Eds). Biopolitics and the 'Obesity Epidemic': Governing Bodies. New York: Routledge.

Lee, J., \& MacDonald, D. (2010). 'Are they just checking our obesity or what?' The healthism discourse and rural young women. Sport, Education, and Society, 15(2), 203-219.

McVey, G., Gusella, J., Tweed, S., \& Ferrari, M. (2009). A controlled evaluation of web-based training for teachers and public health practitioners on the prevention of eating disorders. Eating Disorders, 17, 1-26.

Patton, M. Q. (2002). Qualitative research and evaluation methods. Thousand Oaks, CA: Sage.

Pinhas, L., McVey, G., Walker, K., Norris, M., Katzman, D., \& Collier, S. (2013). Trading health for a healthy weight: The uncharted side of healthy weights initiatives. Eating Disorders, 21, 109-116.

Rail, G. (2009). Canadian youth's discursive construction of health in the context of obesity 
discourse. In J. Wright \& V. Harwood (Eds). Biopolitics and the 'Obesity Epidemic': Governing Bodies. New York: Routledge.

Rich, E. \& Evans, J. (2009). Performative health in schools: welfare policy, neoliberalism, and social regulation. In J. Wright \& V. Harwood (Eds). Biopolitics and the 'Obesity Epidemic': Governing Bodies. New York: Routledge.

Wann, M. (2009). Fat studies: An invitation to revolution. In E. Rothbulm \& S. Solovay (Eds.). The Fat Studies Reader (viii-xxv). New York, NY: New York University Press.

Wright, J. (2009). Biopower, biopedagogies, and the obesity epidemic. In J. Wright \& V.

Zhang, Y., \& Wildemuth, B. M. (2009). Qualitative analysis of content. Applications of social research methods to questions in information and library science, 308-319. 


\section{Appendix A}

\section{Dove Club Mission Statement}

Sir Isaac Brock Public School launches the DOVE CLUB: A first-of-its-kind after-school program in Peel that helps raise awareness for building confidence for young girls!

Sir Isaac Brock Public School's (SIB) Dove Club is a specially designed after-school program aimed at creating a safe, inclusive and supportive environment for young girls who would benefit form confidence and self esteem building. The program's mission statement is to "empower young girls by providing the necessary tools to promote positive self-image and healthy living".

The club aims to achieve its goal of empowering young girls by designing activities and after-school discussions that are centered on the following 4-pillars:

- Health \& Mental Wellbeing: providing young girls with hands on learning experiences that promote and teach them how to lead healthy life styles at an early age.

- Positive Role Modeling: helping students build and maintain positive self-images through role-modeling.

- Relationship Building: equipping young girls with the knowledge and confidence of building positive and healthy relationships (family, friends, classmates).

- Leadership \& Beyond the Classroom: allowing the students to see the connection between classroom activities and the 'real world' by having them interact with, and be exposed to, women in strong leadership roles.

The leaders of the Dove Club program, a group of dedicated teachers, support staff and administrative staff at SIB have spent the past several months researching and designing the program. The idea started with a simple question: "How do we instill positive self image in young girls when they are constantly exposed to a world filled with unrealistic and mixed media messages?" The answer lies in having engaging discussions and experiences where young girls have an opportunity to develop confidence and self-esteem.

The program will run for the remainder of the school year and has received strong administrative support from SIB. Jay Sugunan, Principal of SIB, sees the program as "an opportunity for our group of girls to develop the confidence and self esteem to deal with pressures they encounter on a day to day basis. These experiences are what every girl needs to develop a positive image and lead a healthy and happy life."

The Dove Club Leaders at SIB are extremely excited to begin this journey with its first cohort of 20 students this month! 